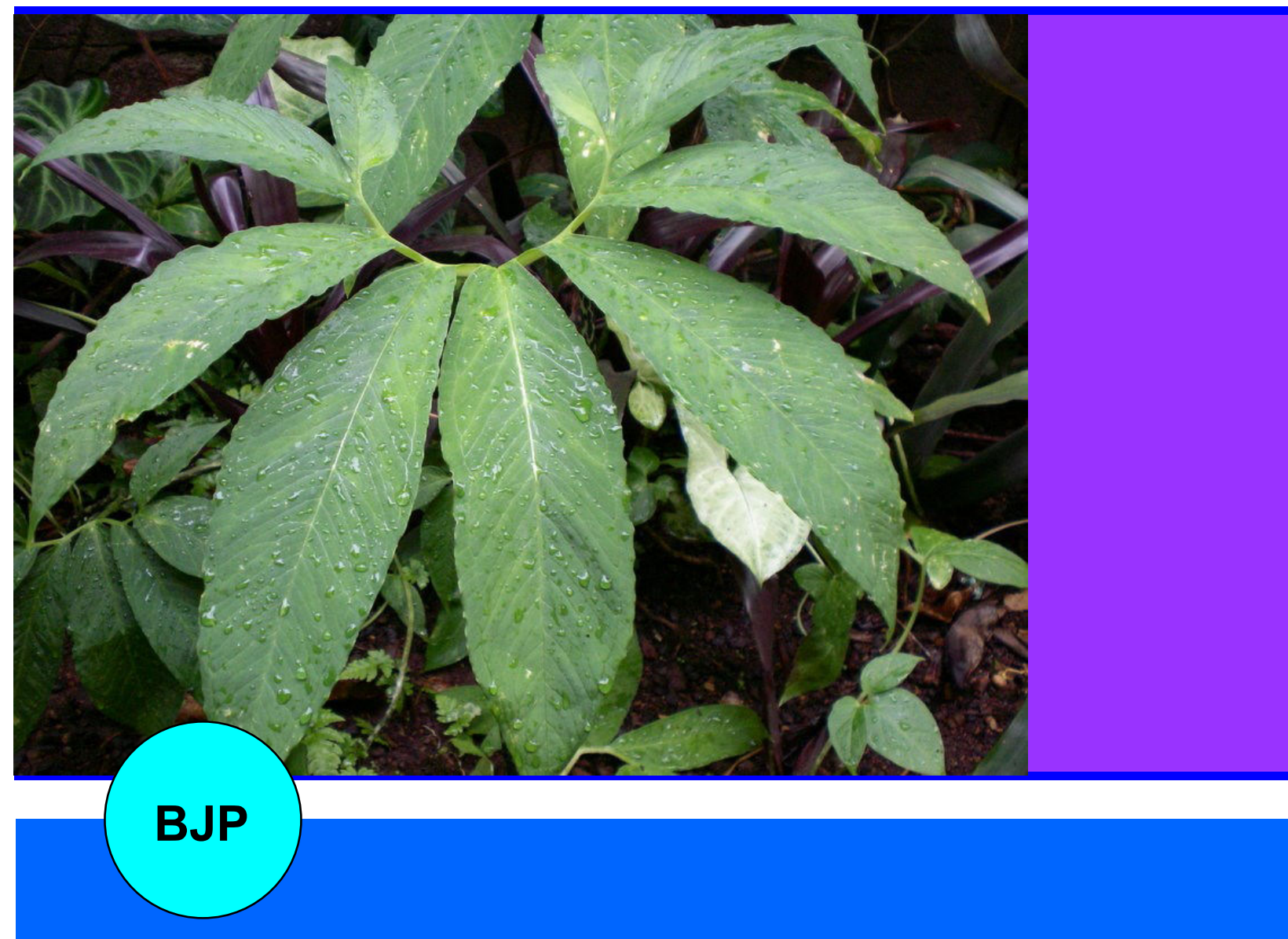

Bangladesh Journal of Pharmacology

Research Article

Functional nature of the spasmolytic effect, phytochemical composition and acute toxicity studies on Sauromatum guttatum 
Abstracted/indexed in Academic Search Complete, Agroforestry Abstracts, Asia Journals Online, Bangladesh Journals Online, Biological Abstracts, BIOSIS Previews, CAB Abstracts, Current Abstracts, Directory of Open Access Journals, EMBASE/Excerpta Medica, Global Health, Google Scholar, HINARI (WHO), International Pharmaceutical Abstracts, Open J-gate, Science Citation Index Expanded, SCOPUS and Social Sciences Citation Index

\title{
Functional nature of the spasmolytic effect, phytochemical composition and acute toxicity studies on Sauromatum guttatum
}

\author{
Nabi Shahi,2, Abdul Jabbar Shahi,2, Manzoor Ahmed4 and Anwarul Hassan Gilani1,3 \\ ${ }^{1}$ Drug Discovery and Natural Products Research Unit; Department of Biological and Biomedical Sciences. The Aga \\ Khan University Medical College, Karachi 74800, Pakistan; ${ }^{2}$ Department of Pharmacy, COMSATS, Institute of \\ Information Technology, University Road, Abbottabad 22060, Pakistan; ${ }^{3}$ Department of Pharmacy, College of \\ Health Sciences, Mekelle University, PO Box 1871, Mekelle, Ethiopia; ${ }^{4}$ Department of Chemistry, University of \\ Malakand, Dir (Lower), KhyberPukhtunkhwa, Pakistan.
}

\begin{tabular}{|c|c|}
\hline \multicolumn{2}{|l|}{ Article Info } \\
\hline Received: & 15 April 2014 \\
\hline Accepted: & 22 April 2014 \\
\hline Available Online: & 26 April 2014 \\
\hline \multicolumn{2}{|c|}{ DOI: 10.3329/bjp.v9i2.18602 } \\
\hline \multicolumn{2}{|c|}{$\begin{array}{l}\text { Cite this article: } \\
\text { Shah N, Shah AJ, Ahmed M, Gilani } \\
\text { AH. Functional nature of the spas- } \\
\text { molytic effect, phytochemical compo- } \\
\text { sition and acute toxicity studies on } \\
\text { Sauromatum guttatum. Bangladesh J } \\
\text { Pharmacol. 2014; 9: 203-07. }\end{array}$} \\
\hline
\end{tabular}

\section{Abstract}

The aim of the present work was to study the functional nature of the potential spasmolytic effect of the crude extract of Sauromatum guttaum. It was found positive for the presence of alkaloid and tannins. In isolated rabbit jejunum preparation, $S$. guttaum caused inhibition of spontaneous and high $\mathrm{K}^{+}(80 \mathrm{mM})$-induced contractions, with respective $\mathrm{EC}_{50}$ values $(95 \%$ confidence intervals) of $1.5 \mathrm{mg} / \mathrm{mL}(0.7-3.0)$ and $1.2 \mathrm{mg} / \mathrm{mL}(0.8-1.6)$, similar to verapamil. Inhibition of high $\mathrm{K}^{+}$-induced contractions suggests $\mathrm{Ca}^{++}$ antagonistic effect. The $\mathrm{Ca}^{++}$channel blocker activity of $S$. guttaum was confirmed when pre-treatment of the tissues with extract $(0.3-3 \mathrm{mg} / \mathrm{mL})$ caused a rightward displacement in the $\mathrm{Ca}^{++}$concentration-response curves. Moreover, in the acute toxicity test, S. guttaum was found safe up to the dose of $3 \mathrm{~g} / \mathrm{kg}$. The findings of the current study suggest that the S. guttaum exhibited spasmolytic activity, possibly mediated through inhibitory effect on $\mathrm{Ca}^{++}$entry and was found safe and this current study provides first evidence to the potential use of this plant as antispasmodic and can play a possible role as antidiarrheal.

\section{Introduction}

Sauromatum guttatum Schott., (Syn: S. vencsum) belongs to the family Araceae and is locally known as "Sanp Ki Booti" and commonly called as "Voodoo lilly or Snake Plant" (Baquar, 1989). It is a shade loving plant and found in the Northern areas of Pakistan. The plant has not been traditionally explored for its medicinal uses, although the family Araceae has wide reputation in the traditional medicine. However, Acorus calamus belongs to family Araceae has traditionally been used in a variety of conditions, such as diarrhea, spasm, colic, flatulence and asthma (Baquar, 1989; Gilani et al., 2006). Similarly, we also have reported A. calamus as antispasmodic (Gilani et al., 2006), vasomodulator (Shah et al., 2009) and bronchodilator (Shah et al., 2010).

To our knowledge, there is no report in the literature on pharmacological and or biological activities of S. guttatum. The present study was therefore carried out to investigate the potential usefulness of S. guttatum in hyperactive gut disorders using in vitro pharmacological protocols.

\section{Materials and Methods}

\section{Plant materials}

Crude extract of the rhizome of S. guttatum was obtained from HEJ Research Institute of Chemistry, Interna- 
tional Center for Chemical and Biological Sciences, University of Karachi, Karachi, Pakistan. A voucher specimen (Sg-231) was deposited at the herbarium of the same Institute.

\section{Preliminary phytochemical analysis}

Crude extract of S. guttatum was tested for the presence of different phytochemical constituents, such as saponins, flavonoids, flavanols, flavones, tannins, phenols, coumarins, sterols, terpenes, alkaloids and anthraquinones by using methods described previously (Edeoga et al., 2005).

\section{Drugs and standards}

The following reference chemicals were obtained from the sources specified: acetylcholine chloride, potassium chloride, calcium chloride and verapamil (Sigma Chemical Company, USA). All other chemicals used were of the highest purity grade. Stock solutions were made in distilled water and the dilutions were made fresh in normal saline on the day of experiment.

\section{Animals}

Local rabbits $(1.5-2 \mathrm{~kg})$ of either gender used in the study were given water ad libitum and a standard animal diet. The animals were maintained in the animal house facility of the Department of Biological and Biomedical Sciences, the Aga Khan University and Hospital, Karachi, Pakistan. Experiments performed complied with the rulings of the Institute of Laboratory Animal Resources, Commission on Life Sciences, National Research Council (NRC, 1996).

\section{Isolated rabbit jejunum preparations}

The isolated tissue experiments were carried out as previously described (Gilani et al., 2005; Shah et al., 2011a; Khan et al., 2012). The animals had free access to water but were fasted for 24 hours before the experiment. The animals were sacrificed by cervical dislocation and segment of the jejunum about 2-3 cm long was removed. The intestinal contents were removed by flushing with Tyrode's solution and placed in Petri dishes containing Tyrode's solution. The tissues were constantly aerated with carbogen gas (5\%carbon dioxide in oxygen). The composition of the Tyrode's solution was as follows in $\mathrm{mM}$ : $\mathrm{KCl} 2.7, \mathrm{NaCl} 136.9$, $\mathrm{MgCl}_{2} 1.1, \mathrm{NaHCO}_{3} 11.9, \mathrm{NaH}_{2} \mathrm{PO}_{4}$ 0.4, glucose 5.6 and $\mathrm{CaCl}_{2} 1.8$ ( $\mathrm{pH}$ 7.4). These tissues were then mounted in $10 \mathrm{~mL}$ tissue baths containing Tyrode's solution. Temperature was maintained at $37^{\circ} \mathrm{C}$ and aerated with carbogen gas. An initial tension of $1 \mathrm{~g}$ was applied to each tissue and kept undisturbed for an equilibrium period of $30 \mathrm{~min}$ with physiological solution changed every five min.

\section{Effects of the extract on isolated rabbit jejunum}

At the end of equilibration period, control responses to a sub-maximal concentration $(0.3 \mathrm{mM})$ of acetylcholine were obtained and the tissue presumed stable only after the reproducibility of the said responses. Under these experimental conditions, rabbit jejunum exhibits spontaneous rhythmic contractions, allowing testing the relaxant (spasmolytic) activity directly without the use of an agonist (Gilani et al., 2005; Shah et al., 2011a).

\section{Determination of calcium antagonist activity}

To understand the possible mechanism of action, the extract was tested on $\mathrm{KCl}$-induced contractions in rabbits' jejunum preparation (Farre et al., 1991). Extract of S. guttatum and standard, such as verapamil were then added cumulatively to obtain concentrationdependent inhibitory responses (van-Rossum, 1963). The relaxation of jejunal preparations, pre-contracted with $\mathrm{K}^{+}(80 \mathrm{mM})$ was expressed as percent of the control.

For the confirmation of possible $\mathrm{Ca}^{++}$entry blocking activity of the crude extract, the tissues were allowed to stabilize in normal Tyrode's solution, which was then replaced with $\mathrm{Ca}^{++}$-free Tyrode's solution containing EDTA. An incubation of 20-30 min was given in order to remove $\mathrm{Ca}^{++}$from the tissues and surroundings. This solution was further replaced with $\mathrm{K}^{+}$-rich and $\mathrm{Ca}^{++}$ free Tyrode's solution, having the following composition (mM): $\mathrm{KCl} 50, \mathrm{NaCl} 91.04, \mathrm{MgCl}_{2} 1.05, \mathrm{NaHCO}_{3}$ 11.90, $\mathrm{NaH}_{2} \mathrm{PO}_{4}$ 0.42, glucose 5.55 and EDTA 0.1 . Following an incubation period of $30 \mathrm{~min}$, control concentration-response curves of $\mathrm{Ca}^{++}$were constructed. When the control CRCs of $\mathrm{Ca}^{++}$, were found superimposable, the tissues were pre-treated with the plant extract for 40-50 min to test the possible calcium entry blocking effect. The concentration-response curves of $\mathrm{Ca}^{++}$were re-constructed in the presence of different concentrations of the crude extract and verapamil.

\section{Acute toxicity test}

The method previously described by (Gilani et al., 2005) was adopted. Briefly, 15 mice in three groups five in each were used in the experiment. The test was performed using increasing doses of the crude extract of $S$. guttatum (1-3 g/ kg body weight), given orally, in $10 \mathrm{~mL} / \mathrm{kg}$ volume to different groups serving as test groups. Another group of mice was administered saline $(10 \mathrm{~mL} / \mathrm{kg})$ served as negative control. The mice were allowed food ad libitum and kept under regular observation for 6 hours while the lethality was recorded after 24 hours.

\section{Statistics}

All data expressed are mean \pm standard error mean (SEM) and the median effective concentration $\left(\mathrm{EC}_{50}\right.$ values) with $95 \%$ confidence intervals (CI). The statistical parameter applied to the Student's t-test (paired or unpaired) with $\mathrm{p}<0.05$ as significantly different (GraphPAD program, GraphPAD, San Diego, Ca, USA), 


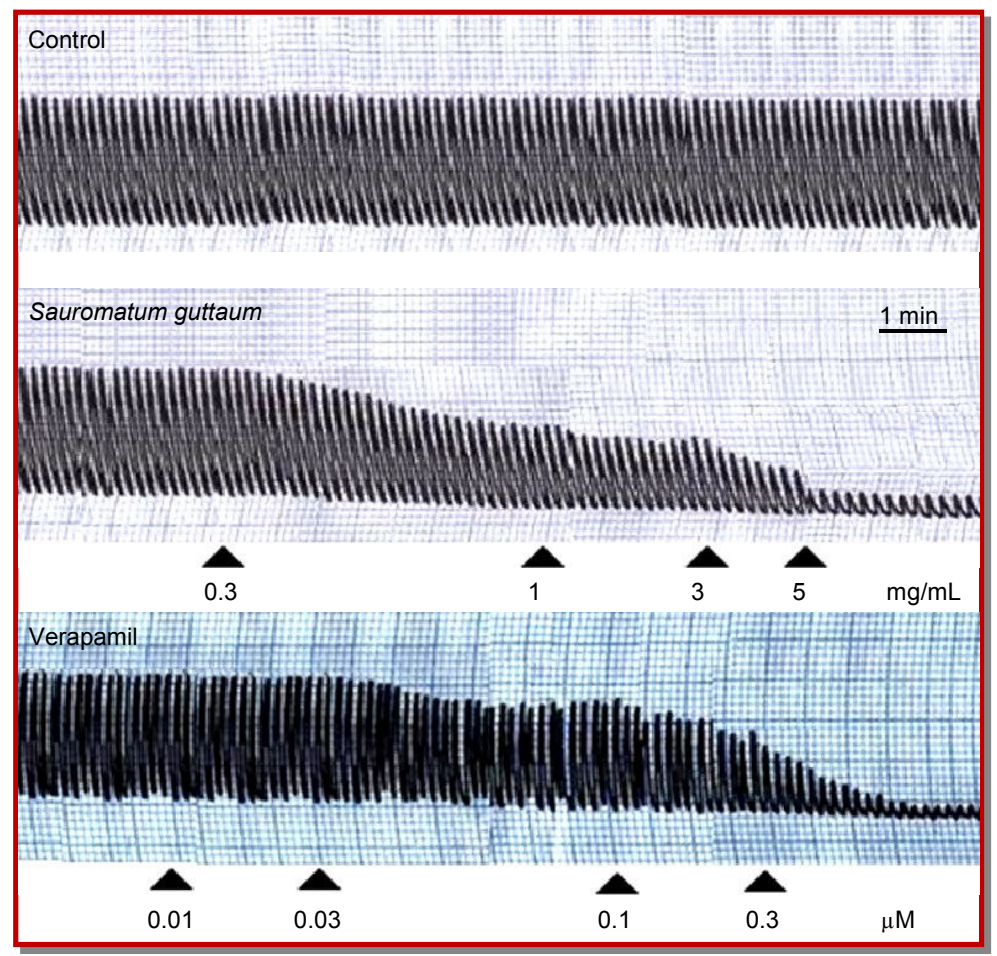

Figure 1: A representative tracing shows the spasmolytic effect of the crude extract of S. guttaum and verapamil on spontaneous contractions in isolated rabbit jejunum preparation

concentration response curves were analyzed by nonlinear regression (GraphPAD program).

\section{Results and Discussion}

In isolated rabbit jejunum preparations, cumulative addition of the crude extract of S. guttatum and verapamil suppressed the spontaneous contractions (Figure 1). The median effective concentration $\left(\mathrm{EC}_{50}\right.$ value) of extract was $1.5 \mathrm{mg} / \mathrm{mL}$ (0.7-3.0), as shown in Figure 2A, this shows intestinal smooth muscle relaxant (spasmolytic) activity.

The contraction of smooth muscle preparations including rabbit jejunum is dependent upon an increase in the cytoplasmic free $\left[\mathrm{Ca}^{++}\right]$, which activates the contractile elements (Karaki, 1987). The increase in cellular $\mathrm{Ca}^{++}$occurs either through influx via voltagedependant $\mathrm{Ca}^{++}$channels or release from intracellular stores in the sarcoplasmic reticulum. Periodic depolarization and repolarization regulates the spontaneous movements of the intestine and at the height of depolarization, the action potential appears as a rapid influx of $\mathrm{Ca}^{++}$via voltage-dependant $\mathrm{Ca}^{++}$channels (Brading, 1981).

Intracellular and extracellular calcium stores also exchange with one other that are responsible for the periodic depolarization and repolarization of jejunal tissues (Abouzid et al., 2008). Hence, it is suggested that the inhibitory effect of $S$. guttatum crude extract on spontaneous movements of rabbit jejunum may be due to interference either with the $\mathrm{Ca}^{++}$release or with the $\mathrm{Ca}^{++}$influx through voltage-dependant $\mathrm{Ca}^{++}$channels.

We previously observed that the spasmolytic constituents present in different medicinal plants mediate their effect through $\mathrm{Ca}^{++}$channel blockade (Gilani et al., 2005; Shah et al., 2010; Khan et al., 2011; Shah et al., 2011b). To see, whether the spasmolytic effect of the crude extract of $S$. guttatum in the current study is mediated through inhibition of calcium entry, a high concentration of $\mathrm{K}^{+}(80$ $\mathrm{mM}$ ) was introduced to produce sustained contraction. Crude extract of $S$. guttatum was then added in a cumulative fashion, where it caused a dose-dependent relaxation of the induced contraction with $\mathrm{EC}-50$ value of $1.2 \mathrm{mg} / \mathrm{mL}(0.8-1.6)$ suggesting inhibitory effect on calcium entry (Figure 2A). The curves resembled those of verapamil (Figure 1 and $2 \mathrm{C}$ ).

Figure 2C and D, show respectively, the effect of the extract and verapamil on the $\mathrm{Ca}^{++}$concentrationresponse curves in isolated rabbit jejunum preparations, constructed in $\mathrm{Ca}^{++}$-free medium. Values shown are mean \pm SEM $(n=3-8)$.

The contraction induced by high $\mathrm{K}^{+}(80 \mathrm{mM})$ is dependent on the entry of $\mathrm{Ca}^{++}$through voltagedependant $\mathrm{Ca}^{++}$channels (Bolton, 1979). It is evident that, subs-tances which can inhibit high $\mathrm{K}^{+}$-induced contractions is therefore, considered to have a possible 


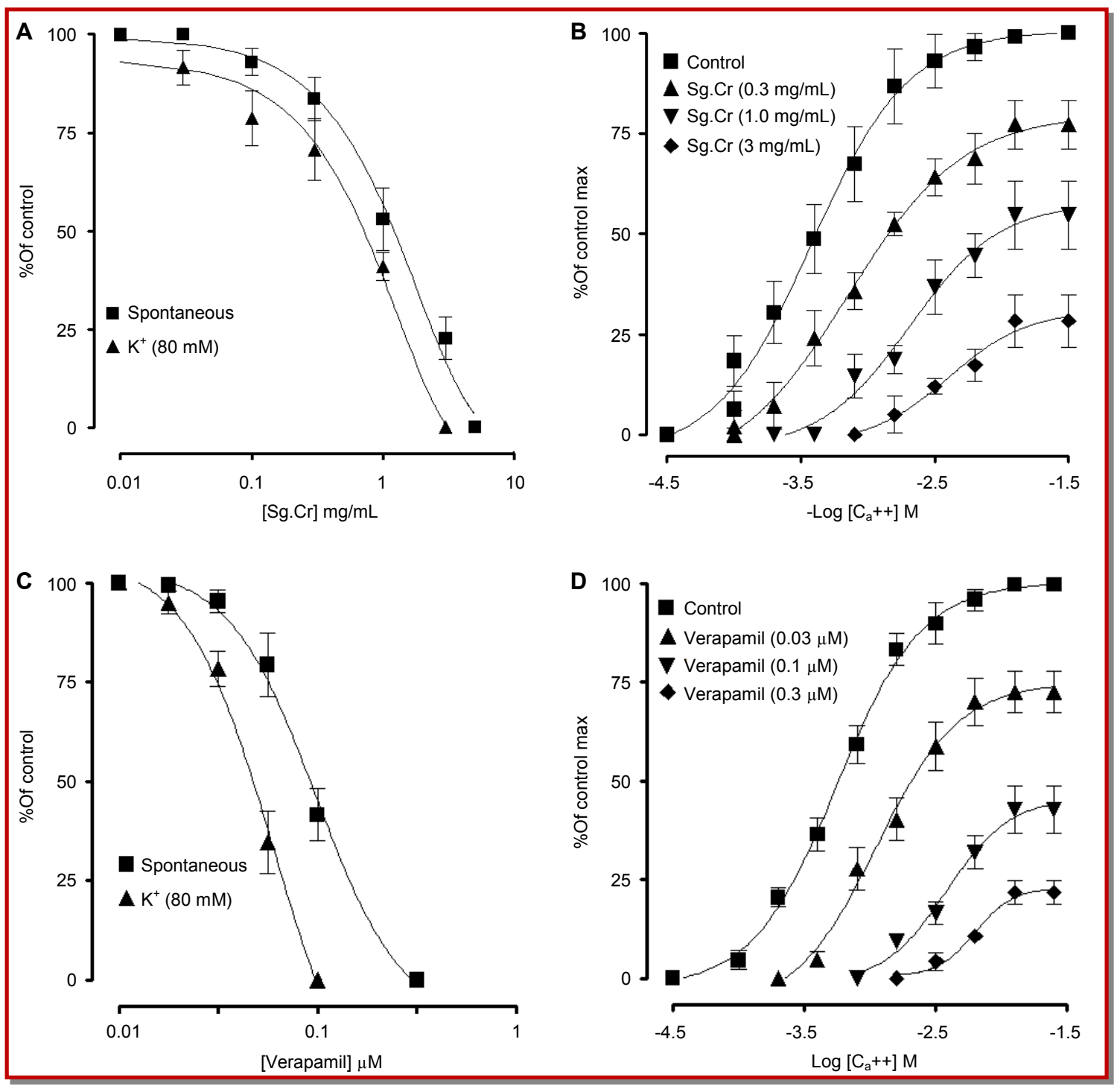

Figure 2: The concentration response curves (CRCs) of the crude extract of S. guttatum (A) and verapamil (C) on spontaneous and high $\mathrm{K}+(80 \mathrm{mM})$-induced contractions in isolated rabbit jejunum preparations. The CRCs on the right panel represents calcium curves in the absence and presence of the crude extract (B) and verapamil (D) showing dose-dependent rightward shift and suppression of maximum response in the calcium curves

calcium entry blocking effect (Godfraind et al., 1986). Thus the inhibition of high $\mathrm{K}^{+}(80 \mathrm{mM})$-induced contraction of rabbit jejunum by the crude extract of $S$. guttatum may reflects inhibitory effect on the $\mathrm{Ca}^{++}$entry through voltage-dependant $\mathrm{Ca}^{++}$channels. This hypothesis was further strengthened when pre-incubation of the jejunal preparations with the extract $(0.3-3 \mathrm{mg} / \mathrm{mL})$ caused a rightward displacement in the $\mathrm{Ca}^{++}$concentrations-response curves (Figure 2C), similar to that caused by verapamil (Figure 2D) (Fleckenstein, 1977). The rightward displacement may be attributed to the presence of phytochemicals like alkaloids and tannins as these types of compounds in medicinal plants has been shown to have calcium entry blocking activity (Kai et al., 1998; Hwang et al., 2001).

The results of the current study suggest that the $S$. guttatum extract possesses antispasmodic activity. It is possible to suggest here that the antispasmodic activity of the extract may be due to calcium entry blocking effect, which is considered useful as antispasmodic (Brunton, 1996; Khan et al., 2013). Therefore, the presence of calcium channel antagonizing constituents in the crude extract of $S$. guttatum may be the possible mechanism for its spasmolytic activity. Additionally, early studies have reported that, $\mathrm{Ca}^{++}$channel blocker are also known having role in managing diarrhea (Brunton, 1996), therefore, further study of the extract will be interested to explore anti-diarrheal activity of this plant.

In acute toxicity study, the crude extract of $S$. guttatum was found safe in mice up to the dose of $3 \mathrm{~g} / \mathrm{kg}$. After 24 hours no mortality or any other apparent behavioral 
abnormalities were observed.

We provided here the first pharmacological evidence that the crude extract of $S$. guttatum possesses spasmolytic effect, which is mediated through the presence of $\mathrm{Ca}^{++}$entry blocking constituent(s) and the extract was found safe up to the dose of $3 \mathrm{~g} / \mathrm{kg}$. Further insight into the chemical constituents and molecular characterization of the effect will be worthwhile.

\section{References}

Abouzid S, Elshahaat A, Ali S, Choudhary MI. Anti-oxidant activity of wild plants collected in Beni-Sueif governorate, Upper Egypt. Drug Disc Thera. 2008; 2: 286-88.

Baquar SR. Medicinal and poisonous plants of Pakistan. Karachi, Printas, 1989.

Bolton TB. Mechanisms of action of transmitters and other substances on smooth muscle. Physiol Rev. 1979; 59: 606718 .

Brading AF. How do drugs initiate contraction in smooth muscles? Trends Pharmacol Sci. 2: 161-65.

Brunton LL. Agents affecting gastrointestinal water flux and motility; emesis and antiemetics; bile acids and pancreatic enzymes. In: Goodman and Gillman's The Pharmacological basis of therapeutics. Hardman JG, Limbird LE, Molinoff PB (eds). New York, McGraw Hill, 1996, pp 917-36.

Edeoga HO, Okwu KE, Mbaebie BO. Phytochemical constituents of some Nigerian medicinal plants. Afr J Biotechnol. 2005; 4: 685-88.

Farre AJ, Columbo M, Fort M, Gutierrez B. Differential effects of various Ca++ antagonists. Gen Pharmacol. 1991; 22: 17781.

Fleckenstein A. Specific pharmacology of $\mathrm{Ca}++$ in myocardium, cardiac pacemakers and vascular smooth muscle. Rev Pharmacol Toxicol. 1977; 17: 149-66.

Gilani AH, Shah AJ, Ahmad M, Shaheen F. Antispasmodic effect of Acorus calamus Linn., is mediated through calcium channel blockade. Phytother Res. 2006; 20: 1080-84.

Gilani AH, Shah AJ, Ghayur MN, Majeed K. Pharmacological basis for the use of turmeric in gastrointestinal and respiratory disorders. Life Sci. 2005; 76: 3089-3105.

Godfraind T, Miller RMW. Calcium antagonism and calcium entry blockade. Pharmacol Rev. 1986; 38: 321-416.
Hwang KH, Han YN, BH. H. Inhibition of calmodulin-dependent calcium-ATPase and phosphodiesterase by various cyclopeptides and peptide alkaloids from the Zizyphus species. Arch Pharmacal Res. 2001; 24: 202-06.

Kai L, Wang ZF, Xiao JS. L-type calcium channel blockade mechanisms of panaxadiol saponins against anoxic damage of cerebral cortical neurons isolated from rats. Zhongguo Yao Li Xue Bao. 1998; 19: 455-58.

Karaki $\mathrm{H}$. Use of tension response to delineate the modes of action of vasodilators. J Pharmacol Methods. 1987; 18: 1-21.

Khan A, Rehman NU, AlKharfy KM, Gilani AH. Antidiarrheal and antispasmodic activities of Salvia officinalis are mediated through activation of $\mathrm{K}+$ channels. Bangladesh J Pharmacol. 2011; 6: 110-16.

Khan M, Rehman NU, Khan AU, Gilani AH. Pharmacological basis for the medicinal use of Morus alba in gut and airways disorders. Bangladesh J Pharmacol. 2012; 7: 289-98.

Khan M, Shah AJ, Gilani AH. Antidiarrhoeal and antispasmodic activities of Vitex negundo Linn. are mediated through $\mathrm{Ca}++$ channel blockade. Bangladesh J Pharmacol. 2013; 8: 317-22.

NRC. National Research Council. Guide for the care and use of laboratory animals. Washington DC, National Academy Press, 1996.

Shah AJ, Begum S, Hassan SI, Ali SN, Siddiqui BS, Gilani AH. Pharmacological basis for the medicinal use of Psidium guajava leave in hyperactive gut disorders. Bangladesh J Pharmacol. 2011a; 6: 100-06.

Shah AJ, Gilani AH. Blood pressure lowering and vascular modulator effects of Acorus calamus extract are mediated through multiple pathways. J Cardiovasc Pharmacol. 2009; 54: 38-46.

Shah AJ, Gilani AH. Bronchodilatory effect of Acorus calamus and its constituents is mediated through inhibition of phosphodiesterases, calcium channel and muscarinic receptors. J Ethnopharmacol. 2010; 131: 471-77.

Shah AJ, Zaidi MA, Sajjad M, Hamidullah, Gilani AH. Antidiarrheal and antispasmodic activities of Vincetoxicum stocksii are mediated through calcium channel blockade. Bangladesh J Pharmacol. 2011b; 6: 46-50.

van-Rossum JM. Cumulative dose-response curves. II. Techniques for the making of dose-response curves in isolated organs and the evaluation of drug parameters. Arch Int Pharmacodyn. 1963; 143: 299-330.

\section{Author Info \\ Anwarul Hassan Gilani (Principal contact) \\ ' e-mail: anwar.gilani@aku.edu}

